"3. Recurrence of granulation from both Stages III and IV indicates the difficulty of bringing about a permanent cure of trachoma. Yet such recurrence does not exceed 12.5 per cent. in Stage III and 13.46 per cent. in Stage IV, and is largely due to the insanitary conditions of the students' houses.

"4. In the case of chronic conjunctivitis persistent application of 2 per cent. silver nitrate solution in the severer cases, and yellow oxide ointment in the others has proved quite satisfactory, total percentages of cure being 88.8.

"5. Notwithstanding the conditions of the school children, exposed as they are to the insanitary circumstances of their homes, as well as to frequent attacks of ophthalmia during the vacation months in summer, the treatment of trachoma in schools is arresting the disease within the period of two scholastic years at the rate of 75.4 per cent. Such a result is considered very satisfactory in schools as treatment does not interfere with the curriculum and gives the students a chance of perfect cure within three years."

\title{
CORRESPONDENCE
}

\section{THE SCLERAL STITCH IN ADVANCEMENT OPERATIONS}

\section{To the Editor of The British Journal of Ophthalmology}

SIR,-The note under the above heading in the journal for January, 1926, leads me to draw attention again to a method I described at the Oxford Ophthalmological Congress a few years back, by which, without the aid of any especially devised instrument, the insertion of the scleral stitch can be effected, not only with comparative ease, but-inasmuch as the track for the needle and suture is made before they are inserted-with the certainty that they are not too deep.

The method consists of utilizing an ordinary sickle-shaped cutting needle with a straight back, preferably in an all-metal handle. Make a needle track where desired in the sclera; before inserting the suture, the needle is withdrawn and the suture inserted by simply passing it through the already made track, using an ordinary needle holder. The use of a Harman's "needle lifter" at that end of track where the point of needle will come out helps.

The heaviness, solidity, and length of the metal cutting needle, and the fact that it is straight gives, during use, a sense of security 
and certainty which can only be appreciated by actual trial. An essential point for success is that the greatest width of the cutting part of the needle be not less than the width of the needle-carrying suture which is going to be used.

Yours truly,

Arthur Greene.

NOR WICH.

January 23, 1926.

\section{OBITUARY NOTICES}

The death of Dr. Samuel Lewis Ziegler took place on January 4, 1926, from pneumonia, in Philadelphia. He was 64 years of age. He graduated in 1885 in medicine at the University of Pennsylvania, and subsequently visited most of the European clinics including London, Paris, Berlin, and Vienna. He was appointed Resident Physician at the Wills Eye Hospital in 1887, followed in 1889 by the appointment of Assistant Surgeon to the same institution. This post he occupied until 1896. In 1889 he became chief Ophthalmic Surgeon at St. Joseph's Hospital, and from 1901 until his retirement from the office some years ago, Attending Surgeon at the Wills Eye Hospital. He was a corresponding member of many European ophthalmological congresses. Bucknell University conferred on him the honorary degree of D.Sc. in 1901, and Lafayette University that of D.Sc. in 1915 . He published many papers on ophthalmic subjects, and, at the time of his death was engaged on his work " The Surgery of the Eye." $\mathrm{He}$ introduced a cautery operation for entropion and ectropion, and the sickle-knife which bears his name is well known to all ophthalmologists.

The death of Dr. Robert Stanley Minnes took place at his home in Ottawa from pneumonia on December 27, 1925. He was in his 56th year. He was a student of Queen's University, Canada, where he graduated in Arts with a gold medal in mathematics in 1890, qualifying later in 1893 in medicine with the M.D., C.M. After a short time as House Surgeon in the Kingston General Hospital he came to England and studied at the Royal London Ophthalmic Hospital. In 1895 he was appointed Resident Surgical Officer to the Birmingham and Midland Eye Hospital, which post he held till 1897. He worked at the Throat Hospital, Golden Square, and visited Vienna and some other Continental clinics. 